\title{
Introduction
}

\section{Students with disabilities in post-secondary educational settings}

\author{
John Kregel \\ Vinginia Commonwealth University, 1314 West Main Street, Richmond, VA 23284-2011, USA
}

\begin{abstract}
Rapid changes in our nation's economy, including an increasing reliance on technology and demographic changes in the work force, have increased the value of post-secondary education for individuals with disabilities attempting to maximize their employment potential. Individuals who participate in higher education are (1) more likely to be employed and (2) earn higher wages than other individuals. As a result the number of individuals with disabilities accessing post-secondary educational opportunities has increased dramatically in recent years. Despite serious administrative, programmatic, attitudinal and financial obstacles, students with disabilities today comprise between $5 \%$ and $10 \%$ of students entering postsecondary education. High school programs are focusing increased attention on preparing students to enter colleges and universities of their choice. At the post-secondary level, many colleges have developed high quality special student service units and other programs to allow students to benefit from their post-secondary opportunities. In addition, newly emerging rehabilitation technologies are allowing many individuals to transfer their successful educational experiences into long-term employment success.

The articles contained in the issue have been developed to reflect the breadth and diversity of issues directly related to the participation of indi-
\end{abstract}

viduals with disabilities in post-secondary educational settings. Success in these settings requires (1) careful planning and preparation at the high school level, (2) administrative, programmatic, and social supports at the post-secondary level, (3) a recognition that the amount and type of supports required varies widely across individuals, and (4) an understanding that success in educational settings does not automatically translate to success in employment settings.

The first article, written by Dr. Sally Scott, provides a comprehensive overview of the array of services and supports available to students with disabilities in colleges and universities. At one level, access to post-secondary educational opportunities is a matter of compliance with clearly defined federal laws and regulations, specifically the Americans with Disabilities Act (ADA) and Section 504 of the Rehabilitation Act. However, it is important to remember that access in higher education involves more than simply equal opportunity for program admission. Student recruitment, treatment of students academic requirements and instruction, housing, financial and employment assistance, and non-academic services and all other facet of college life are impacted by the ADA and Section 504. The ability of colleges and universities to respond to these needs varies widely. Dr. Scott illustrates the diversity in scope 
and quality of student support services in areas such as the types of accommodations provided, the policies and procedures developed to guide program implementation, the extent of student participation in decision-making, and availability of specialized services.

The ability of students with disabilities to access and benefit from post-secondary educational opportunities is built on the preparation received at the high school level. Acquiring the necessary pre-requisite skills and course credits, preparing for college entrance examinations, selecting the type of college and program that meets an individual's needs and proceeding through the admissions process are all key activities that require careful planning and assistance at the secondary level. Dr. Sharon deFur and her colleagues discuss the wide array of issues facing adolescents with disabilities and their families as they begin to seek out post-secondary opportunities. Particular attention is paid to the need for effective planning at the secondary level, identifying the types of supports individuals may require when they enter post-secondary settings, and the role of parents in the transition process.

The next two articles describe the types of support services needed by various groups of individuals with disabilities. In the first, Dr. Debra Petty and Marcia Kolvitz discuss the specific obstacles faced by individuals who are deaf or hard of hearing. Of special significance are the results of focus groups held with students to identify the major barriers encountered during their post secondary educational experiences and the strategies found to be most successful in addressing those obstacles. The experiences shared by the focus group members reflect the fact that students with disabilities encounter more than programmatic barriers. Attitudes, lack of finances, and other issues also challenge students attempting to succeed in higher education.

In the second article, Jennifer Zvi and Lee Axelrod describe the nationally recognized program for students with learning disabilities at the University of California at Northridge. Of particular importance is the emphasis the program places on individualized planning processes, insuring that each student receives the amount of support desired. The program is also distinguished by the wide array of services available, from training and support provided to faculty members, to instruction and training on learning strategies, peer support groups and transition services.

It is not enough for colleges and universities simply to admit students with disabilities, provide only mandated services and supports, and limit accommodations to the removal of architectural barriers. In a powerful article, Stephen Gilson describes the need for supportive, peer-directed social environments that will encourage students with disabilities to develop a sense of empowerment and self-direction. The article chronicles recent trends in universities throughout the country in which students with disabilities are working to develop an increased sense of common identity, drawing strength from shared experiences, and focusing on the social, political, communal, and cultural aspects of disabilities. To achieve these goals, Dr. Gilson emphasizes the need for college and university administrators to collaborate with students with disabilities to fulfill their legal and social responsibilities. Students should be considered the experts in defining needed disability services. Importantly, university disability services should be administered, directed, and staffed by people with disabilities, who themselves, are in the best position to assist students in identifying the services and supports which will enable them to compete successfully with their peers.

While the articles described above reflect the tremendous increase in post-secondary educational opportunities for students with disabilities, less attention has been directed toward the transition needs and career attainment rates of students who have completed the educational programs and attempt to enter the work force. Too often, individuals with disabilities are discovering that a college degree does not guarantee a meaningful, rewarding career. Learner accommodations that are effective in educational settings may not be appropriate or transferable to employment settings. In the final article in the series, Elizabeth Getzel, my colleague at Virginia Commonwealth University, describes a comprehensive 
transition model designed to enable individuals to avoid the trap of long-term unemployment and lengthy dependence on federal financial subsidies that plague many adults with disabilities.

The transition model - termed the Employment Connection Program - emphasizes student control of the career planning process and utilizes existing college or university resources and community support. The program stresses student choice, ongoing career planning throughout the student's academic experience, extensive involvement of employers in the planning process, and coordination of university and community services to prepare students for success in the world of work. The program capitalizes on newly developed technologies such as person-centered planning, supported employment, compensatory strategies and rehabilitation engineering. 